Open Access Journal of Internal Medicine

ISSN: 2638-5279

Volume 2, Issue 2, 2019, PP: 15-23

\title{
Governmentality, Public Policy and Self-Management
}

\section{Prof. Jason Powell}

Associate Dean of Health and Social Care, The University of Staffordshire, UK. Jason.Powell@staffs.ac.uk

*Corresponding Author: Prof. Jason Powell, Associate Dean of Health and Social Care, The University of Staffordshire, UK.

\section{Abstract}

This paper explores the incidence and consequence of public policies in the United Kingdom through the conceptual lens of governmentality (Foucault, 1977). This paper focuses on England and considers the implications of the shift of the inter-relationship between the State, and social care. In many ways, public policy provides three pathways for vulnerable adults. First, as independent self-managing consumers with private means and resources; Second, as people in need of some support to enable them to continue to self manage; Third, as dependent and unable to commit to self-management. Governmentality that derives from the work of Michel Foucault provides an innovative analytical framework through which to view public policy and practice that is largely governed by discourses of personalisation, safeguarding, capability and risk.

Keywords: Public Policies, Governmentality, Care, Self-management, Personalization, and Risk.

\section{INTRODUCTION}

This article explores the incidence and consequence of public policies for older people through the poststructuralist use of governmentality (Foucault, 1977). This will enable us to critically consider the implications of the configuration of the relationship between the state and social care. This re-figuring constructs an ambiguous place for vulnerable people: they feature either as a resource - captured in the idea of the 'active citizen', as affluent consumers, volunteers or providers of child care - or as a problem in the context of poverty and risk especially the consequences of post BREXIT.

In many ways, policy provides three trajectories for older people: first, as independent self managing consumers with private means and resources; second, as people in need of some support to enable them to continue to self-manage; and third, as dependent and unable to commit to self-governance. Governmentality provides the theoretical framework through which to view policy and practice that is largely governed by discourses of personalisation, safeguarding, capability and risk.

\section{GOVERNMENTALITY AND RELEVANCE OF Policy Domains}

Exploring the role that public policy plays in shaping the social context of older people through the analytical lens of governmentality is to adopt a specific approach to the analysis of this phenomenon. The use of such an analysis reflects the way that neo-liberal forms of government - such as those that have existed in the UK and most of the western world since the late 20th century - manage populations. The article's interest is in the subtle mechanisms through which the behaviour of individuals is shaped, guided and directed without recourse to coercion (Foucault 1991, Rose 1999; Powell 2017).

Central to this process is the concept of the selfmanaging citizen-consumer engaged in an endless processofdecision-makingin consumer-basedmarkets. The process is supported by an array of discourses of self-management and associated social practices that are disseminated through social institutions such as factories and workplaces, the media, banks and retail outlets, health and welfare services, schools and universities, churches, and leisure and community organisations. These discourses penetrate deep into family life and personal relationships, regulating 
Governmentality, Public Policy and Self-Management

behaviour by locating individuals in a network of obligations towards themselves and others.

Simultaneously a 'felt' responsibility for a particular locality or an imagined community is produced (Rose 1996), whereby identity is affirmed. Examples of this process can be identified in the commitments to promoting social capital of the Blair / Brown Labour administrations or the 'Big Society' idea of the Cameron / Clegg Coalition government, Theresa May government and newly formed Boria Johnson administration. Citizenship is avowed by participating in consumer-based activities and the maintenance of an accredited life-style (Miller 1993). The process has been described as an 'ethic of the self' (Davidson, 1994) and is supported by an ever increasing array of experts embedded in a range of social systems such as physicians, health professionals, social workers, beauticians, personal trainers and financial advisers (Rose 1999; Powell 2018).

Parallel to this process the state is concerned with gathering statistics that help define the population and maintain a level of surveillance that affords the management of risk. Affluent older persons are identified, measured, and then grouped with similar persons. Once described, the characteristics of this group are disseminated via a range of media that suggest personality, aspirations and life chances. Similarly, older people requiring support - the physically infirm, cognitively impaired, widowed etc - are identified, measured, grouped and their characteristics disseminated.

For most individuals the level of surveillance is best described as a light touch sufficient to maintain the disciplinary focus of the state in a way that is both fleeting and total (Rose and Miller 1992, Rose 1996, 1999, Turner 1997, Knowles 2001; Powell 2017). However, for those whose behaviour is thought to be high risk or for those who fail to conform to the notion of the self-managing consumer-citizen, this surveillance is more oppressive, leaving them vulnerable to victimblaming (Osborne 1997).

This produces the three pathways referred to earlier where those individuals who are willing and able to commit to the market and to self-manage experience a particular combination of options and opportunities while those who, for whatever reason, fail to meet this commitment experience a different and more limited set of options that are often oppressive and impersonal
(Rose, 1996; 1999; Petersen, 1997; Gilleard and Higgs 2005; Phillipson 2013). The consequence of this for the 'government of government' (Foucault 1977) is that its role is clearly circumscribed. It must set out to ensure that basic freedoms are respected, but acknowledge the importance of the family and the market for the management of the care of older people.

\section{The Neo-Liberalization of Public Policy}

Analysing the impact of neo-liberalism from different perspectives, both Tony Giddens (1998) and Ulrich Beck (2005) have claimed that citizens and the state are faced with the task of navigating themselves through a changing world in which globalization has transformed personal relations and the relationship between State and the individual. In the period since 1979, both Conservative and Labour Governments have adopted a neo-liberal stance characterized by an increasing distancing of the state from the direct provision of services. Instead, government operates through a set of relationships where the state sets standards and budgets for particular services but then contracts delivery to private, voluntary or third

sector organizations (Powell 2017). The underpinning rationale is that this reconfiguration of the state retains a strong core to formulate public policy alongside the dissemination of responsibility for policy implementation to a wide range of often localized modes such as social work and social workers.

Neo-liberal governance emphases enterprise as an individual and corporate strategy, supported by its concomitant discourse of marketisation and the role of consumers. The strategy increasingly relies on individuals to make their own arrangements with respect to welfare and support, accompanied by the rhetoric of choice, self-management, responsibility and obligation (Jordan, 2005) - even where public money is used to pay for services.

Neo-liberalism in the 21st century is perhaps the dominant contemporary means through which boundary adjustments are being made and rationalized, with far-reaching consequences for both States and markets. The project of neo-liberalism is evolving and changing, while the task of mapping out the moving terrain of boundaries for social work and older people's experiences is only just realistically beginning; it is long overdue. In this context, the territorial state defined by geographical space is not so much withering away as being increasingly 
enmeshed in webs of economic interdependencies, social connections and political power.

This, in turn, leads to the development of a denser and more complex set of virtual, economic, cultural and political spaces that cut across traditional distinctions between inside and outside, public and private, left and right (Beck, 2005). In this sense, possibly the most influential piece of contemporary neo-liberal public policy came with the implementation of the National Health Service and Community Care Act (1990). This brought with it the purchaser / provider split and care management; it laid the foundations for subsequent policy initiatives such as the cash-for-care schemes (Direct Payments and Individual Budgets) which provide the core of the 'personalization agenda'. Much of this is inspired by global developments in the way care is funded (Powell \& Gilbert, 2011; Phillipson 2013) but which is constantly challenged by the isolationist Trump administration in the US.

In the second decade of the 21st Century, we have entered an accelerated phase of retraction by the UK state in relation to its role in the provision of welfare, with actual levels of support being reduced. Rhetorically, the Conservative/Liberal Democrat coalition was committed to the idea of the 'Big Society' which translates into a vision of individuals and communities coming together to work to resolve common concerns, as this Cabinet Office statement confirms:

'We want to give citizens, communities and local government the power and information they need to come together, solve the problems they face and build the Britain they want. We want society - the families, networks, neighbourhoods and communities that form the fabric of so much of our everyday lives - to be bigger and stronger than ever before. Only when people and communities are given more power and take more responsibility can we achieve fairness and opportunity for all'. (The Cabinet Office 2010, www.cabinetoffice.gov.uk/news/building-bigsociety accessed 08/04/2019).

Since Theresa May came into power and replaced by the Boris Johnson as Prime Minister much of the care agenda has been pushed to one side in term of policy formulation and implementation. The main reason has been the focus on the consequences of BREXIT.

This 'felt responsibility' for a particular locality or 'imagined community' is core to the neo-liberal project which, alongside active citizenship, provides the discursive structure for volunteering in the third sector and the promotion of a network of voluntary activity. In the process, the disciplinary effect of the selfmanaging individual is reproduced at neighbourhood and community levels.

The third sector is crucial in such a scenario, playing a key role by inter-connecting a new partnership between government and civil society. Promoting this relationship is core to the functions of the Office of Civil Society established by the coalition government in 2010 whose role was to enable people to develop social enterprises, voluntary and charitable organizations while promoting the independence and resilience of the sector.

Evidence of public intervention to support the renewal of community through local initiatives not only advances the status of professional social work organisations but manages the day-to-day operations of social work. Equality, mutual respect, autonomy and decision-making through communication with socially disadvantaged and/or dependent older people come to be seen as integral to the sector and provide an opportunity to encourage socially excluded groups and communities to participate as active citizens in, rather than be seen as a potential burden to, community engagement (Gilleard and Higgs, 2005). As stated, the consequences of BREXIT in 2019 will put a strain on community engagement if the UK Treasury predicts an economic recession.

Neo-liberalism is especially concerned with inculcating a new set of values and objectives orientated towards incorporating citizens as both players and partners in a marketized system. As such, social workers are exhorted to become entrepreneurs in all spheres and to accept responsibility for the management of civic life (Beck, 2005; Powell 2017). There is also an apparent dispersal of power (Foucault, 1977) achieved through establishing structures in which social workers and older people co-produce governance through their own accountable choices (Gilbert and Powell 2010).

As Powell (2017) has observed, this is directly connected with the political rationality that assigns primacy to the autonomization of society in which the paradigm of enterprise culture comes to dominate forms of conduct including that of social work with older people. The very significance of autonomization is that there is a strategic aim to diffuse the public 
sector's monolithic power to encourage diversity and fragmentation of provision of care to private and voluntary sectors.

Such a strategy constitutes a fundamental transformation in the mechanisms for governing social life. It has combined two interlinked developments: a stress on the necessity for enterprising subjects and the resolution of central state control with older people articulates with a desire to promote organizational social work autonomy through service provision. Each of these has re-conceptualized previous patterns of social relationships within and between those agencies and their clients.

The crucial point to note is that there is great contingence and variation in such relationships, with unevenness across time and space. These relationships involve the development of new forms of statecraft some concerned with extensions of the neo-liberal market-building project itself (for example, trade policy and financial regulation), some concerned with managing the consequences and contradictions of marketization (for example, public policy process).

It also implies that the boundaries of the state and the market are blurred and that they are constantly being renegotiated (Kendall, 2003). Theoretically the paper identifies the need to engage with key social debates about the future of welfare and care and individual relationships to and expectations of the State. One of the central debates has been on neo-liberalism and its impingement on repositioning of older people and collective organization of modern society.

\section{Integrating Care Services: Public Policy AND OLDER PEOPLE}

The previous sections of this article have sought to identify the changing relationship between the State and older people by exploring the notion of governmentality. The discussion now moves on to consider more specifically how public policy shapes the social context for older people. Here we need to take account of the social and economic backdrop that frames older people's experiences of support and care. In the process, we identify key developments in public policy such as personalisation, risk and safeguarding, and their congruence with the neo-liberal project.

The neo-liberal project constructs as its core subject the self-managing citizen-consumer who is actively making choices within markets. In the context of care and welfare this involves individuals making choices about the type of support they want and who will provide that support as the range of providers is expanded in two broad ways. First, new providers enter the market providing new services or providing services in new ways. Second, and of key importance, people seeking support move outside of the segregated confines of welfare services to obtain services from mainstream providers (Dickinson and Glasby, 2010). Such innovative moves may include, for example, a physical exercise programme from a sports centre instead of physiotherapy, an art course instead of time at a day centre, a holiday abroad instead of respite care (Powell, 2017).

In many ways, the 'Personalisation Agenda' as it is set out in 'Putting People First' (2007) represents the high point of the neo-liberal project with respect to welfare. This approach is largely constructed through a framework of earlier policy which includes the Community Care (Direct Payments) Act (1996), Independence Wellbeing and Choice (DH, 2005) and Our Health, Our Care, Our Say (DH, 2006).

This was then supplemented by the Coalition Government with the publication of Capable Communities and Active Citizens (DH, 2010) and Think Local, Act Personal (2011) which aim to tie the shift to self-directed support outlined by the 'Personalization Agenda' more closely to the previous notion of the Big Society replaced by a relentless focus on BREXIT. The discourses that articulate within this policy framework are those familiar to neo-liberalism: independence, choice, freedom, responsibility, quality, empowerment, active citizenship, partnership, the enabling state, co-production and community action.

Alongside this policy framework are constructed a number of specific techniques that target individuals, families and communities. These include an alternative method of allocating cash to individuals in the form of individual budgets, on-line self-assessment to augment local authority assessment processes, and community-based advocacy to support life style choices. In addition, commissioning models and approaches are being developed that aim to promote opportunities by responding proactively to the aspirations of people receiving services. Self-directed support is significant as it breaks with the tradition where state support is mediated by professionals who undertake assessments and organisations that are funded to provide places. 
Even in more contemporary times, when individuals might be afforded a choice between two or more places or opportunities, the organizations received funding from the state. Under personalization, assessment takes place to identify the overall budget a person is entitled to receive, but the money is allocated to the individual either through a direct payment or by establishing an individual budget. In terms of governmentality, the 'Personalization Agenda' effectively shifts the responsibility for organizing support from the state to the individual needing support via a form of cash transfer - something that Powell (2017) describes as the privatization of risk.

The advance of the 'Personalisation Agenda' has drawn support from a number of sources including specific groups of service users (Phillipson, 2013), politicians from across the spectrum (Ferguson 2007; Phillipson 2013), and social care managers and social workers (Samuel, 2009). One possible reason for this is that personalization is conceptually ambiguous, making it difficult to disagree with its basic premise while it retains a number of contradictory ideas (Powell 2017). However, it has also drawn criticisms particularly from older people who have reported lower psychological well-being due, possibly, to added anxiety and stress due to the burden of organizing their own care (Glendinning et al. 2008).

Today, there are also concerns expressed regarding the impact of personalization on the integration and stability of adult social care; this includes unease with the emphasis on individualistic solutions which may undermine democratic and collective approaches to transforming existing services or developing new services (Powell 2017). Doubts have also been expressed over the readiness of the third sector to take on the demands of providing support.

At the same time, while the disaggregating of budgets might suit some small innovative niche organizations the disruption of funding streams may be perceived as a threat and bring instability to larger more mainstream third sector organizations (Dickinson and Glasby, 2010). Other issues arise due to the somewhat fragmented process of implementation and the differences that occur in service provision between urban and rural areas (Manthorpe and Stevens, 2010).

Ferguson (2007), drawing on the Canadian experience, suggests that personalization favours the better educated, may provide a cover for cost-cutting and further privatization and marketization of services, while the employment conditions of personal assistants may give rise to concern. Governmentality enables the identification of the parallel concerns of neo-liberalism - the promotion of the self-managing individual and the management of risk (Phillipson 2013). So far we have explored self-management in social care through the promotion of self-directed care as part of the 'Personalization Agenda'. We now turn to the management of risk. This can be seen to take two forms, each dealt with by different elements of public policy. Protection from the risks posed by others are managed through safeguarding and policy such as No Secrets (DH and HO, 2000) [England and Northern Ireland] or In Safe Hands (2000) [Wales].

In Capable Communities and Active Citizens (2010) the government clearly states that safeguarding is central to personalisation. Risks posed by the individual to their own person are contained by the Mental Capacity Act (2005) and its powers to override individual choice or replace autonomy by measures such as Enduring or Lasting Powers of Attorney or the Court of Protection.

No Secrets has provided the basis of policy towards safeguarding for over a decade. It defined abuse in the context of an abuse of trust and the Human Rights Act (1998) and set out a model for inter-agency working that has been adopted by local authorities in England and Northern Ireland. In Wales the corresponding policy is 'In Safe Hands'. No Secrets drew from experience in relation to safeguarding children and described a number of categories of abuse including physical, sexual, neglect and financial abuse. However, it lacked the legal imperative to share information that is included in safeguarding children.

Furthermore, the environment within which 'No Secrets' operates has seen considerable change since implementation. One key change was the discursive shift from vulnerable adult to safeguarding that took account of the dangers of victim blaming implied in the notion of vulnerable adults while the concept of safeguarding suggests the focus should be on the environment within which people find themselves.

However, this rhetorical shift has not removed abuse. A recent prevalence survey suggests levels of abuse of between 2.6 per cent and $4 \%$, depending on how 
Governmentality, Public Policy and Self-Management

the estimates are constructed (O'Keeffe et al. 2007). Action on Elder Abuse, one of the organisations that sponsored the study uses evidence of under reporting to reinterpret this estimate as 9 per cent (Powell 2017).

In 2008, the Department of Health set up a consultation over the review of No Secrets where a number of organizations including the Association of Directors of Adult Social Care and Action on Elder Abuse campaigned for a legislative framework to put adult protection on the same footing as child protection (Phillipson, 2013). However, no significant changes in guidance or legal status occurred as the Coalition government maintained that safeguarding was an issue for local communities; thus maintaining the distance between the State and individuals.

Discourses of safeguarding operate and produce their effects via the multiple interactions of institutions embedded in local communities. Furthermore, the advent of personalization has seen an increasing focus on financial abuse as direct payments and rules about eligibility for State support for care costs increase opportunities for financial exploitation, fraud and theft.

No Secrets treats financial abuse as an artifact of other apparently more serious forms of abuse. However, in 2004, the House of Commons Select Committee identified financial abuse as possibly the second most commonly occurring form of abuse experienced by older people.

Estimates in the USA suggest that financial abuse is the most common form of abuse with up to 40 per cent of older people victims (Gorbien, 2011).

\section{ConClusion}

This article has explored the place that public policy plays in shaping the social context of older people. To achieve this we have drawn on the concept of governmentality to identify how neo-liberal forms of government construct older people as active consumers within welfare markets shifting the responsibility for organizing support from the State to the individual (Phillipson 2013). The contemporary context for working with older people who need some form of support is formed by the relationship between personalization and safeguarding.
These set out the twin pillars of neo-liberal governance, namely self-management through self-directed support and the management of risk through safeguarding (Powell, 2017). Individuals are constructed as citizen-consumers actively making choices about what their needs are and identifying appropriate services, sometimes with the support of advocates or workers such as social workers in a process of co-production. In circumstances where risks are considered too high the power to make choices can be temporarily or permanently restricted (Phillipon 2013).

\section{REFERENCES}

[1] Alzheimer's Society. (2011). What is Dementia: Factsheet 400. http://www.alzheimers.org.uk accessed 12/04/2019

[2] Bayliss, J \& Sly, F. (2010). Aging across the UK, Newport: Office of National Statistics.

[3] Beck, U. (2005). Power in the Global Age, Cambridge: Polity Press.

[4] Bigby, C. (2004). Aging with a Lifelong Disability, London: Jessica Kingsley.

[5] Burchell, G. (1993). Liberal government and techniques of the self, Economy and

[6] Burholt, V \& Windle, G. (2006). The material resources and well-being of older people, NewYork: Joseph Rowntree Foundation.

[7] Davidson, A, I. (1994). Ethics as ascetics: Foucault, the history of ethics, and ancient thought. In Gutting, G. [ed.] The Cambridge Companion to Foucault, Cambridge: Cambridge University Press, pp. 115 - 140.

[8] Department of Health (1996). Community Care (Direct Payments) Act, London: TSO.

[9] Department of Health (2005). Independence Wellbeing and Choice: Our vision for the future of social care for adults in England, London: TSO.

[10] Department of Health (2006). Our Health, Our Care, Our Say: A new direction for community Services, London: TSO.

[11] Department of Health (2007). Putting People First: Shared vision and commitment to the 
Governmentality, Public Policy and Self-Management

transformation of adult social care, London: TSO.

[12] Department of Health (2010). A Vision for Adult Social Care: Capable Communities and Active Citizens, London: TSO.

[13] Department of Health (2011). Think Local, Act Personal: A sector wide commitment to moving forward with personalisation and community based support, London: TSO.

[14] Department of Health and Home Office (2000). No Secrets: guidance on developing and implementing multi-agency policies and procedures to protect vulnerable adults from abuse, London: TSO.

[15] Department of Health and Social Security (1990). National Health Service and Community Care Act, London: TSO.

[16] Department of Work and Pensions (DWP) (2005). Older people in low-income households, London: TSO

[17] Dickinson, H. \& Glasby, J. (2010). The personalization agenda: implications for the third Sector, Third Sector Research Centre: Working paper 30, Birmingham: TSRC

[18] Dominelli, L. (2004). Theory and Practice for a Changing Profession, Cambridge: Polity Press.

[19] Estes, C. (1979). The Aging Enterprise, San Francisco: Jossey Bass.

[20] Department of Health (2009). Evaluation of Individual Budgets. London,

[21] Evaluation of the Individual Budgets Pilot Programme: Final Report, Public policy Research Unit, University of York, York

[22] Ferguson, I. (2007). Increasing User Choice or privatizing Risk? The Antinomies of

[23] Personalization, British Journal of Social Work, 37(3): 387 - 403.

[24] Foucault, M. (1977). Discipline and Punish, London: Allen Lane

[25] Foucault, M. (1991). Governmentality, in Burchell, G., Gordon, C. and Miller, P. [eds.], The
Foucault Effect: Studies in Governmentality. Hemel Hampstead: Harvester Wheatsheaf.

[26] Giddens, A. (1998). The Third Way: The Renewal of Social Democracy, Cambridge: Polity Press.

[27] Gilbert, T \& Powell, J. L. (2010). Power and Social Work in the United Kingdom: A Foucauldian Excursion, Journal of Social Work, 10(1), pp.3 22

[28] Gilleard, C. \& Higgs, P. (2005). Contexts of Aging: Class, Cohort and Community,

[29] Cambridge: Polity Press.

[30] Goldfield, T. (2005). Wealth of the Nation 2005, Brighton: CACI

[31] Gorbien, M. (2011). Protecting Against fraud and Financial Abuse, Chicago, Illinois: Rush University Medical Center

[32] HM Government (2010). The Cabinet Office: The Big Society www.cabinetoffice.gov.uk/ news/ building-big-society accessed 08/04/2011)

[33] Hoff, A.(2008). Tackling Social Exclusion of older People - lessons from Europe, Working paper 308, Oxford: Oxford Institute of Aging/University of Oxford

[34] House of Commons Health Select Committee, Elder Abuse (2004). Second Report of Session, Vol. 1. Report, together with formal minutes, London: TSO.

[35] Hughes, B. \& Mtejuka, E, M. (1992). Social Work and Older Women, in M, Langan \& L, Day [eds.] Women, Oppression and Social Work: Issues in anti-discriminatory practice, London: Routledge.

[36] Johnson, N. (1999). The personal social services and community care, in M, Powell [ed.] New Labour, New Welfare? The 'Third Way' in British Public policy, Bristol: Policy Press

[37] Jordan, B. (2005). New Labour: Choice and values, Critical Public policy, 25(4), pp.427 - 446

[38] Jordan, B. \& Jordan, C. (2000). Social Work and the Third Way: Tough love as public policy, London: Sage.

[39] Kemshall, H. (2002). Risk, Public policy and Welfare, Buckingham: Open University Press. 
Governmentality, Public Policy and Self-Management

[40] Kendall, J. (2003). The Voluntary Sector: Comparative perspectives in the UK, London: Routledge.

[41] Kerr, B., Gordon, J., MacDonald, C. \& Stalker, K. (2005). Effective Social Work with Older People: A paper prepared for the Scottish Executive, Stirling: Social Work Research Unit, University of Stirling.

[42] Knowles, C. (2001). Cultural perspectives and welfare regimes: The contributions of Foucault and Lefebve, in P, Chamberlayne., A, Cooper. \& M, Rustin [eds.] Welfare and Culture in Europe: Towards a New Paradigm in Public policy, London: Jessica Kingsley, pp. 240 - 254.

[43] Kuh, D. \& Shlomo, B, Y. (2004). A Life Course Approach to Chronic Disease Epidemiology, Oxford: Oxford University Press

[44] MacDonald, C. (2004). Older People and Community Care in Scotland: A review of recent Research, Edinburgh: TSO.

[45] Manthorpe,J.\&Stevens, M.(2010).Understanding the potential impact of personalization for social work with rural older people, British Journal of Social Work, 40(5), pp.1452 - 1469

[46] Marshall, T. H. (1950). Citizenship and social class and other essays, Cambridge: Cambridge University Press.

[47] Mental Capacity Act (2005). London: TSO.

[48] Miller, T. (1993). The Well-Tempered Self: Citizenship, Culture and the Postmodern Subject, Baltimore: John Hopkins University Press.

[49] Newman, J., Glendinning, C. \& Hughes, M. (2008). Beyond modernisation? Social care and the transformation of welfare governance, Journal of Public policy, 37(4), pp.531-57.

[50] O'Keeffe, M., Hills, A., Doyle, M., McCreadie, C., Scholes, S., Constantine, R., Tinker, A., Manthorpe, J., Biggs, S., \& Erens, B. (2007). UK Study of Abuse and Neglect of Older People: Prevalence Survey Report, Prepared for Comic Relief and the Department of Health. London: National Centre for Social Research/King's College London

[51] Ogg, J. (2005). Social exclusion and insecurity among older Europeans: the influence of welfare regimes, Aging \& Society, vol. 25, pp.69-90

[52] Osborne, T. (1997). Of Health and Statecraft, in A, Petersen. \& R, Bunton [eds.] Foucault: Health and Medicine., London: Rutledge, pp. 173 - 188.

[53] Petersen, A. (1997). Risk, governance and the new public health, in A, Petersen. \& R, Bunton [eds.].Foucault: Health and Medicine, London: Routledge, pp. 189 - 206.

[54] Phillipson, C. (1982). Capitalism and the Construction of Old Age, Basingstoke: Macmillan.

[55] Phillipson, C. (1998). Reconstructing Old Age: New agendas in social theory and Practice, London: Sage.

[56] Phillipson, C. (2008). The Frailty of Old Age, in M, Davies [ed.] The Blackwell Companion to Social Work[3rd Edition], Oxford: Blackwell Publishing

[57] Phillipson, C (2013) Ageing. Bristol: Polity

[58] Philp, I. (2008). Late Life Aging, in M, Davies [ed.] The Blackwell Companion to Social Work [3rdEdition], Oxford: Blackwell Publishing

[59] Poll, C \& Duffy, S. [eds.] (2008). Report of In Control's Second Phase 2005 - 2007, London: In Control Publications

[60] Powell, J, L. \& Gilbert, T. (2011). Personalisation and Sustainable Care, Journal of Care Services Management, 5(2), pp. 79 - 86

[61] Powell, J (2017). Rethinking Aging. New York: Nova Science

[62] Rose N. (1996). The death of the social? Refiguring the territory of government, Economy and Society,25(3), pp.327-356.

[63] Rose, N. (1999). Powers of Freedom: Reframing political thought, Cambridge: Cambridge University Press.

[64] Rose, N. \& Miller, P. (1992). Political power beyond the state: problematics of Government, British Journal of Sociology, 43(2), pp.173-205.

[65] Samuel, M. (2008). No Secrets Review: The key issues, Community Care 20/02/2008.

[66] Samuel, M. (2009). Practitioners back personali- 
Governmentality, Public Policy and Self-Management

sation but call for more support, Community Care Society, 22(3), pp. 267-82

[67] The National Assembly for Wales and the Home Office (2000). In Safe Hands: Implementing Adult Protection Procedures in Wales, Cardiff: The National Assembly for Wales

[68] Thompson, N. (2001). Anti-Oppressive Social Work Practice, Basingstoke: Palgrave
[69] Turner, B. S. (1997). From governmentality to risk: Some reflections on Foucault's contribution to medical sociology, in A, Petersen. \& R, Bunton [eds.] Foucault: Health and Medicine, Routledge: London, Pp. ix-xxi.

[70] Walker, A. \& Walker, C. (eds.): (1997) Britain Divided. London: CPAG.

Citation: Jason Powell. Governmentality, Public Policy and Self-Management. Open Access Journal of Internal Medicine. 2019; 2(2): 15-23.

Copyright: (C) 2019 Jason Powell. This is an open access article distributed under the Creative Commons Attribution License, which permits unrestricted use, distribution, and reproduction in any medium, provided the original work is properly cited. 